\title{
Intersexual conflict influences female reproductive success in a female-dispersing primate
}

\author{
Marie L. Manguette ${ }^{1,2}$ (1) Andrew M. Robbins ${ }^{1} \cdot$ Thomas Breuer $^{2,3} \cdot$ Emma J. Stokes $^{4} \cdot$ Richard J. Parnell $^{4}$. \\ Martha M. Robbins ${ }^{1}$
}

Received: 28 February 2019 / Revised: 12 July 2019 / Accepted: 17 July 2019 / Published online: 12 September 2019

(C) The Author(s) 2019

\begin{abstract}
In group-living mammals, individual efforts to maximize reproductive success result in conflicts and compromises between the sexes. Females utilize counterstrategies to minimize the costs of sexual coercion by males, but few studies have examined the effect of such behaviors on female reproductive success. Secondary dispersal by females is rare among group-living mammals, but in western gorillas, it is believed to be a mate choice strategy to minimize infanticide risk and infant mortality. Previous research suggested that females choose males that are good protectors. However, how much female reproductive success varies depending on male competitive ability and whether female secondary dispersal leads to reproductive costs or benefits has not been examined. We used data on 100 females and 229 infants in 36 breeding groups from a 20-year long-term study of wild western lowland gorillas to investigate whether male tenure duration and female transfer rate had an effect on interbirth interval, female birth rates, and offspring mortality. We found that offspring mortality was higher near the end of males' tenures, even after excluding potential infanticide when those males died, suggesting that females suffer a reproductive cost by being with males nearing the end of their tenures. Females experience a delay in breeding when they dispersed, having a notable effect on birth rates of surviving offspring per female if females transfer multiple times in their lives. This study exemplifies that female counterstrategies to mitigate the effects of male-male competition and sexual coercion may not be sufficient to overcome the negative consequences of male behavior.
\end{abstract}

\section{Significance}

Individual reproductive success is maximized through conflicts and compromises between the sexes in social mammals. In species with high dimorphism, females can experience sexual coercion by males and develop counterstrategies to reduce these costs. We studied this link in western lowland gorillas, which exhibit female secondary dispersal, a strategy that is believed to reflect female choice for the protective abilities of males. We found that females are faced with the dilemma of staying with a silverback at the end of his tenure and risk higher infant mortality versus dispersing and suffering reproductive delays and lower

Communicated by M. A. van Noordwijk

Electronic supplementary material The online version of this article (https://doi.org/10.1007/s00265-019-2727-3) contains supplementary material, which is available to authorized users.

Marie L. Manguette

marie_manguette@eva.mpg.de

Andrew M. Robbins

htram@aol.com

Thomas Breuer

breuer1@gmx.de

Emma J. Stokes

estokes@wcs.org

Richard J. Parnell

parnellmayumba@yahoo.co.uk
Martha M. Robbins

robbins@eva.mpg.de

1 Department of Primatology, Max Planck Institute for Evolutionary Anthropology, Deutscher Platz 6, 04103 Leipzig, Germany

2 Mbeli Bai Study, Wildlife Conservation Society Congo Program, B.P 14537 Brazzaville, Congo

3 World Wide Fund for Nature, Reinhardtstrasse 18, 10117 Berlin, Germany

4 Wildlife Conservation Society, Global Conservation Program, 2300 Southern Boulevard, Bronx, NY 10460, USA 
birth rates. This study shows that female reproductive strategies, namely dispersal, used to counter the effects of sexual coercion by males are not sufficient to overcome the negative consequences of male behavior.

Keywords Gorilla gorilla $\cdot$ Infanticide $\cdot$ Infant mortality $\cdot$ Tenure length $\cdot$ Dispersal costs

\section{Introduction}

Social structures of group-living species are a result of male and female reproductive strategies (Kappeler and van Schaik 2002; Clutton-Brock 2007; Palombit 2015). In most mammals, female reproductive strategies are likely to center on access to food due to the energetic costs and limitations on reproduction caused by gestation and lactation, whereas male reproductive strategies focus on the availability of females that results in male-male competition and sexual coercion (Trivers 1972; Smuts and Smuts 1993). Male-male contest competition can lead to large sexual dimorphism and male monopolization of females (Clutton-Brock 2007; Clutton-Brock and Huchard 2013). In turn, females develop counterstrategies against male coercion and may seek out males that offer protection from conspecifics or predators (Breuer et al. 2009). These divergent reproductive strategies often result in pronounced sexual conflicts (Trivers 1972; Arnqvist and Rowe 2013; Palombit 2015).

Females can suffer the costs of infanticide by males, which is a clear example of sexual conflicts in social mammals and especially in primates (Lukas and Huchard 2014; Palombit 2015). Males commit infanticide to improve their own reproductive success by reducing that of competitors and subsequently siring offspring with the mothers of the infants that were killed, which consequently lowers the fitness of the mothers (Hrdy 1977). After an infanticide, females return to estrous faster and are likely to transfer to and mate with the infanticidal male (Smuts and Smuts 1993). The loss of an infant constitutes a serious fitness cost for females with slow reproductive rates (Pusey and Packer 1994; Palombit 2015). In response, females have developed counterstrategies to infanticide including forming permanent associations with male defenders, remaining with the father until weaning of the infant, emigration to a multimale group, mating with multiple males, or joining a better protector male (Palombit 2015). In species with female philopatry, unweaned offspring are particularly vulnerable to infanticide when an intruder male deposes the current alpha male (Rudran 1973; Packer and Pusey 1983; Swedell et al. 2011; Kalbitzer et al. 2017). During group takeovers, pregnant females or females with young infants do not have many choices because dispersing would leave them vulnerable to infanticide by the male of the new group and therefore, the timing of dispersal is essential. However, infanticide risk by immigrant males during group takeovers can be reduced if females actively disperse to voluntarily join other males during the limited time window between weaning of their last offspring and before conceiving again (Sterck et al. 2005; Robbins 2009). Nevertheless, female dispersal may be an effective counterstrategy to infanticide and may reduce the benefits of males attempting a takeover as males are less likely to risk injury by challenging a dominant male only to find that all females leave for another male (Steenbeek 2000; Janson et al. 2012).

If females gain protection against infanticide by associating with a male and use dispersal as a counterstrategy to infanticide, then female transfer decisions are an expression of female choice based on the protective qualities of rival males (Harcourt and Stewart 2007). This ability to disperse in sexually dimorphic species gives females a certain amount of intersexual power that is not present in female philopatric species (Lewis 2018). In this paper, female dispersal, also called secondary or breeding dispersal, refers to the movement of breeding females who have already left their natal group for other groups and involves a change in reproductive partners (Isbell and Van Vuren 1996; Clutton-Brock and Lukas 2012). While inbreeding avoidance has been considered an explanation for natal dispersal in social mammals, female secondary dispersal can be better explained by socioecological factors such as access to better mating opportunities, better habitat, and reduction of within-group competition or coercion. Female philopatry is often assumed to be more advantageous than dispersing because it assures the knowledge of the home range and offers better opportunities for cooperation with relatives (Clutton-Brock and Lukas 2012). Although female natal dispersal is found in several species of mammals (Strier 1994; Clobert et al. 2012), female secondary dispersal is only known to occur routinely in a handful of mammal species including most social equids, several tropical bats, Thomas langurs, and gorillas in addition to some observations in woolly and spider monkeys (Sterck and Korstjens 2000; Nagy et al. 2007; Di Fiore et al. 2009; Debeffe et al. 2015; Furuichi et al. 2015; Stevenson et al. 2015). It is not well understood why this strategy is so rare, but could be linked to costs of dispersal including loss of habitat familiarity after dispersing (Bonte et al. 2012), higher rates of aggression directed to the dispersers (Isbell and Van Vuren 1996), or reproductive costs such as longer latencies before next reproduction as in dispersing female feral horses (Debeffe et al. 2015).

A female's choice of group and secondary transfer decision may be based on the ability of the current dominant male of her group to provide better protection against infanticide 
compared with other males. Evidence that females seek a male that can provide better protection is suggested by observations that groups with a larger male have more females (Breuer et al. 2012), that dispersal is triggered by the death of an offspring in mountain gorillas (Harcourt et al. 1976; Robbins 2009), or by increased aggression towards the alpha male by extragroup males as in Thomas langurs (Sterck et al. 1997). Variation in male strength and male-male contest competition is expected over different phases of the male dominance tenure, with males predicted to be more vulnerable to competitors when they are not fully grown and are less experienced in the early phase of their tenure or when they passed their prime and have lower competitive ability (Steenbeek 2000; Alberts 2012). Male strength and competitive ability may correlate negatively with age and are likely to vary among males of the same age, because other factors may also play a role such as body size, physical condition, experience, personality, and skills (Plavcan and van Schaik 1997; Arnott and Elwood 2009; Wright et al. 2019). The optimal female reproductive strategy may therefore involve a trade-off between dispersal costs, such as time lost for reproduction, versus the benefits of choosing better protective male (Robbins et al. 2009).

To investigate how female reproductive success may be influenced by the trade-off between dispersal costs and the benefits of being with a better protector male, we analyzed the demographic data of a population of western lowland gorillas (Gorilla gorilla gorilla) from over two decades of continuous observations at Mbeli Bai in the Nouabalé-Ndoki National Park in northern Republic of Congo. Western lowland gorillas have large sexual dimorphism (Parnell 2002) and live almost exclusively in one-male groups, consisting of only one silverback (fully mature adult male), adult females, and immature individuals (Parnell 2002; Gatti et al. 2004; Robbins and Robbins 2018). The one silverback of each group provides protection against infanticide. The risk of infanticide may be especially high after the only male in a one-male group dies, because unweaned offspring are vulnerable as females are forced to join an extra-group male (Watts 1989; Robbins et al. 2013). Female transfer between groups only during intergroup encounters and females have not been observed ranging on their own (Stokes et al. 2003). Group takeovers by extra-group males have not been observed in western gorillas when the silverback of a group is still alive, so male tenures end either with the death of the silverback or the transfer of all adult females to another group. Silverbacks almost always have only one tenure. Female transfer between social units in gorillas is believed to reflect female choice for highquality males because larger silverbacks have more females and lower infant mortality (Caillaud et al. 2008; Breuer et al. 2010). However, females would be expected to transfer when the strength and quality of a male decreases as he ages and approaches the end of his tenure. Dispersal has been associated with reproductive delays for female mountain gorillas
(Robbins et al. 2009), and similar costs can be expected for western lowland gorillas.

We examined the reproductive success of female western gorillas using three variables: the survival probability of their offspring through infancy, the duration of their interbirth intervals (IBI), and the birth rate of surviving offspring (Robbins et al. 2007; Pusey 2012). We hypothesized that females face a trade-off between dispersal costs and the benefits of being with a better protector male. We assumed males to be the best protector males when they are in the middle of their tenure (presumably in their prime) and not as good protectors when they are at the beginning of their tenure (often young and inexperienced) or at the end of their tenure (often old). More specifically, we predicted that (1) infant mortality initially decreases as tenure duration increases due to males approaching their prime, and then, infant mortality increases as silverbacks approach the end of their tenures, due to a decrease in competitive/protective ability, senescence, or higher risk of infanticide if the male dies; and (2) female dispersal is associated with breeding delays that result in longer interbirth intervals and lower surviving birth rates, but is expected to be associated with lower infant mortality.

\section{Methods}

\section{Study population}

Western gorillas were studied at Mbeli Bai, a 12.9-ha swampy forest clearing in the Nouabalé-Ndoki National Park, Republic of Congo (Parnell 2002; Stokes et al. 2003; Breuer et al. 2009). It is unknown whether swampy forest clearings have any influence on our results. We can exclude potential anthropogenic effects influencing the population dynamics of the study subjects because Mbeli Bai is a pristine forest with no legal logging, illegal human activities, or major disease outbreaks observed during the study. We used the demographic data collected by three principal investigators (TB, EJS, RJP) and their site managers/assistants from February 1995 until October 2015 for 55,230 observation hours on 6140 observation days (average $9 \mathrm{~h}$ /day) during nearly continuous daily monitoring (Table S1). We observed the gorillas visiting the clearing from a 9-m-high observation platform overlooking the bai with an almost $100 \%$ visibility, using a combination of spotting scopes, a digital camera, and videos. Gorillas were identified using facial features such as the shape of the brow-ridges, ears and nose prints, body size, and pelage coloration (Parnell 2002; Breuer et al. 2009, 2010). We used age-sex categories based on Breuer et al. (2009) with offspring considered dependent until weaning (4 years of age), females considered adult at 10 years of age, and males at 18 years. Blinded methods were not used in this study. 


\section{Estimates of dates of demographic changes}

A total of 440 gorillas were observed including 229 infants born to 100 adult female gorillas in a total of 36 breeding groups. Because individual gorilla groups did not visit the clearing every day, there were gaps of observation, and dates of birth, presumed death, and dispersal were estimated. We assumed that individuals were resident in a particular group if they were observed in the same group before and after the gaps of observation. Some infants were observed within a few days after birth as confirmed by recent previous observations of the group without them. Beyond that age, birthdates were estimated by comparing morphological and behavioral characteristics with infants of known age (Parnell 2002; Nowell and Fletcher 2007; Breuer et al. 2009). The precision of those birthdates is believed to be within a few weeks for most gorillas who were first observed as infants and within 1-2 years for gorillas who were first observed as they approached adulthood. All analyses were limited to infants for whom the date of births was known to within \pm 45 days. We excluded five cases of twins from all analyses due to the difficulties of raising two offspring simultaneously potentially leading to longer interbirth intervals independently of the variables tested.

Dispersal dates were quantified as the midpoint between the last visit of the group of origin and the first of the group of destination (Stokes et al. 2003; Breuer et al. 2010). When a gorilla disappeared, we were usually unable to determine whether it had died or dispersed. It is unlikely that infants ( $<4$ years) could survive without their mother (Nowell and Fletcher 2007; Breuer et al. 2009), so if the mother was sighted without the offspring when the infant was less than four years of age, we assumed that it had died (as in Breuer et al. 2012). For silverbacks that disappeared, we also assumed they had died because in most cases, the silverbacks were seriously injured or very thin before disappearance (Breuer et al. 2010). We estimated dates of disappearance/death as the midpoint between the last time an individual was observed and the first time the group was seen without him/her. When a silverback died, infants of that group were assumed to have been killed by the new group leader, although a few cases where infants survived the death of their presumed father have been documented (Stokes et al. 2003; Breuer et al. 2012).

We calculated male tenure duration as the interval between the first and last dates that a silverback was observed in association with adult females. Two of those intervals included an intermediate period in which the silverback was not associated with any adult females and those periods with no adult females were subtracted from the tenure duration (51 months and 13 months). Even with 20 years of observation, we had complete tenures for few males ( $n=5$, Fig. 2). For long-lived species such as gorillas which can have tenures of more than 17 years (Hagemann et al. 2018), examining the beginning and the end of the tenures separately can be a useful way of circumventing the lack of complete tenures. Therefore, we used two variables as estimates of tenure duration: the elapsed tenure: the duration since the tenure began and the remaining tenure: the time until the tenure ended (see Figs. 1 and 2). Tenures ended when all females transferred to a different group or when the silverback died. We did not include two tenures that started before the group was first observed and extended beyond the observation period. Male tenure duration was considered a better proxy for male competitive ability than male age in this population because competitive ability is likely to vary among males of the same age and because the birthdates of the males were estimated. Furthermore, the estimated age of the silverback was significantly correlated with the elapsed tenure $(R=0.92, N=136, p=<0.001)$ and the remaining tenure $(R=-0.43, N=58, p=0.001)$.

\section{Analyses of offspring mortality}

We used mixed Cox proportional hazard models to examine the relationships between male tenure duration, female dispersal, and infant survival. Male tenure duration was used to examine the potential effects of their competitive/ protective ability and infanticide risks on infant survival. We fitted two sets of models: one that included only groups that were monitored since the tenure of the silverback began (elapsed tenure, model 1) and another one that used only the groups that were monitored until the tenure ended (remaining tenure, model 2). The response variable was whether the infant survived to age four (yes $=1$, no $=0$ ).

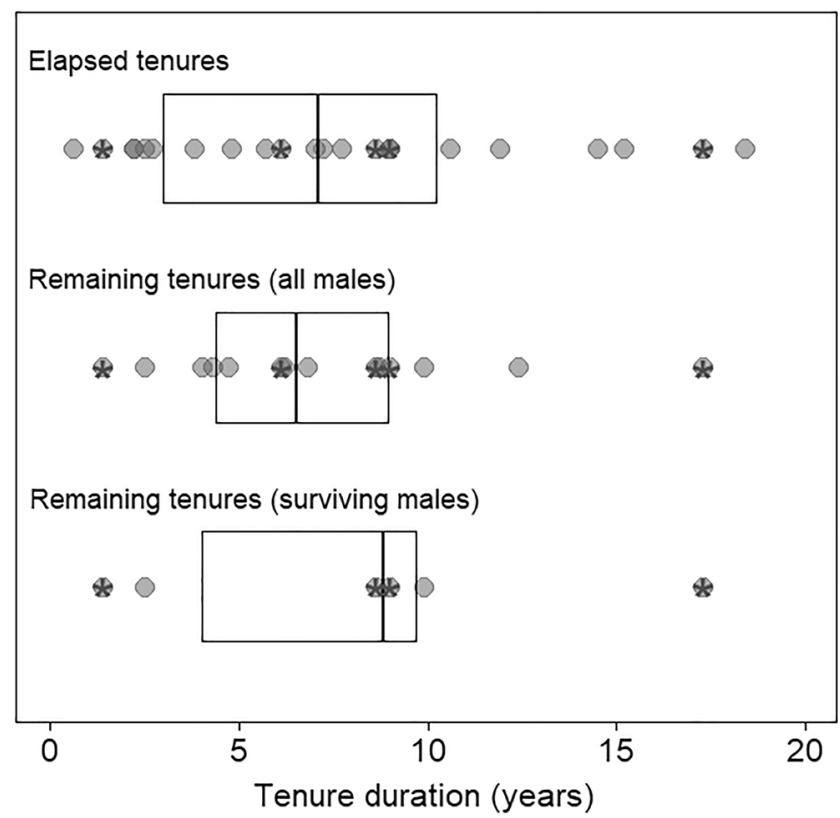

Fig. 2 Duration of the known tenures used in the study (elapsed $(N=22)$, remaining tenures both with all males $(N=14)$, and with only surviving males $(N=6)$ ). Each point represents the tenure of one silverback, the boxes are medians and upper and lower quartiles. The stars are the complete tenures $(N=5)$ 
Fig. 1 Graphical description of tenure duration. "Elapsed tenure" is the duration since the silverback acquired his first female. The "remaining tenure" is the time until the silverback dies or loses his last female
Elapsed tenure

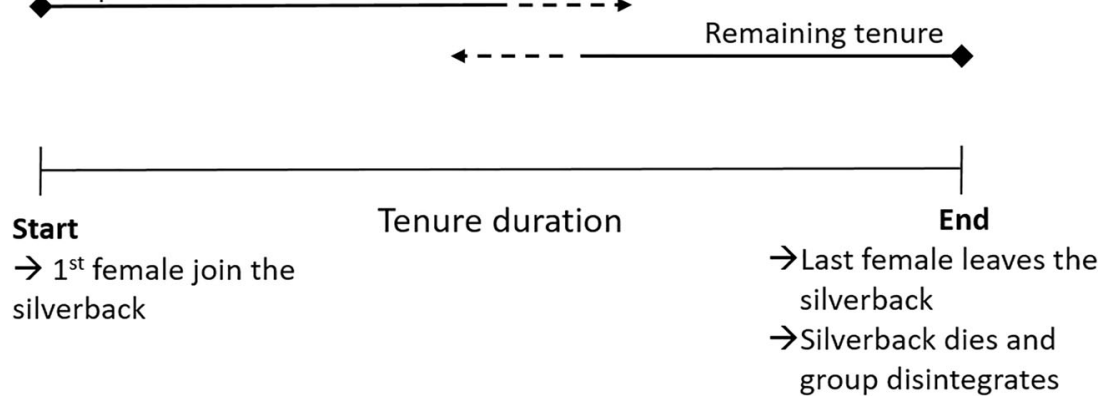

Infants still alive at the end of the study but being below 4 years of age were censored. The predictor variables of the two models were the time elapsed between the tenure's beginning and the infant's birth and the time elapsed between the infant's birth and the tenure's end, respectively. We included a squared term for both the elapsed tenure and the remaining tenure to account for the possibility that we captured more than half of the tenure length. For the remaining tenure model, we fitted two separate models, one model using all tenures that ended (model 2a) to examine the overall risks for females with a silverback nearing the end of his tenure, while a second model used only groups where the silverback survived the end of his tenure (tenure ending with the transfer of the last female) to examine only the risks while the silverback was still alive (by excluding the most obvious cases of infanticide when he died) (model $2 b)$. To be included in the analysis, a tenure needed to be long enough to include at least one infant birth. In models 1 and $2 \mathrm{a}$, we controlled for female age and the number of weaned individuals in a group (group size) when the infant was born, as well as the quadratic terms for those variables because non-linear patterns have been reported in other species (Robbins et al. 2006; Markham et al. 2015). We did not include parity as a control predictor because it was highly correlated with female age and lead to collinearity issues in the models. Sample sizes were too small to include control predictors in model $2 \mathrm{~b}$. To examine the influence of a dispersal event on the survival of the next offspring, we tested whether infants born after a dispersal event were more likely to survive than infants of females that did not disperse (model 3).

We conducted mixed Cox proportional hazard models with the function "coxme" of the "coxme" package (Therneau 2018) in R (R Core Team 2017). We z-transformed (to a mean of 0 and a standard deviation of 1 ) all quantitative predictor variables to obtain more comparable estimates and to ensure model interpretability (Schielzeth 2010). All Cox models included random effect variables for the identity of the mother and the identity of their group. Each model was fitted with the full random slope structure (Table 1). We checked diagnostics for model stability by excluding levels of random effects one at a time from the data set and comparing the estimates derived with those obtained from the model based on all the data; no influential cases were observed. We established the significance of the full models as compared with the null models (comprising only the control predictors as well as the random effects; (Forstmeier and Schielzeth 2011), using likelihood ratio tests (Dobson and Barnett 2008), conducted with the function ANOVA with the argument set to "Chisq".

\section{Analyses of interbirth intervals}

An IBI is defined as the interval in months between two successive births by the same mother. In mountain gorillas, IBIs are shorter after an offspring dies (Robbins et al. 2006). We therefore separated the analysis between surviving birth intervals (SIBI) and death-birth intervals (DBI). Surviving interbirth intervals are defined as the time between the birth of an offspring that survived to the age of 4 years and the next birth by the same mother, whereas death-birth intervals are the time between the death of an infant and birth to the next one. We tested if both SIBI and DBI were longer following a female transfer. To decrease the risk of undetected infants that died shortly after birth, we excluded interbirth intervals of females that were not observed for a period longer than 9 months between when their last offspring reached the age of 4 years (for SIBI) or death of last offspring (for DBI) and birth of the next infant.

To examine the influence of dispersal on the duration of the interbirth interval, we fitted two linear mixed models (LMM) with a Gaussian error structure and an identity link. The response variable was the duration of the SIBI (model $4 \mathrm{a}$ ) and the duration of the DBI (model 4b), respectively. The fixed effects predictor variable was whether the female transferred to a known group during the interbirth interval (yes $=1$, no = 0 ). We excluded interbirth intervals that included involuntary transfers that occur after group disintegration due to the death of the silverback, because these are unlikely to represent female choice. Similar to analysis of infant mortality, we controlled for the age of the mother and the number of individuals $>4$ years of age in the group as well as their squared term when the infant was born. 


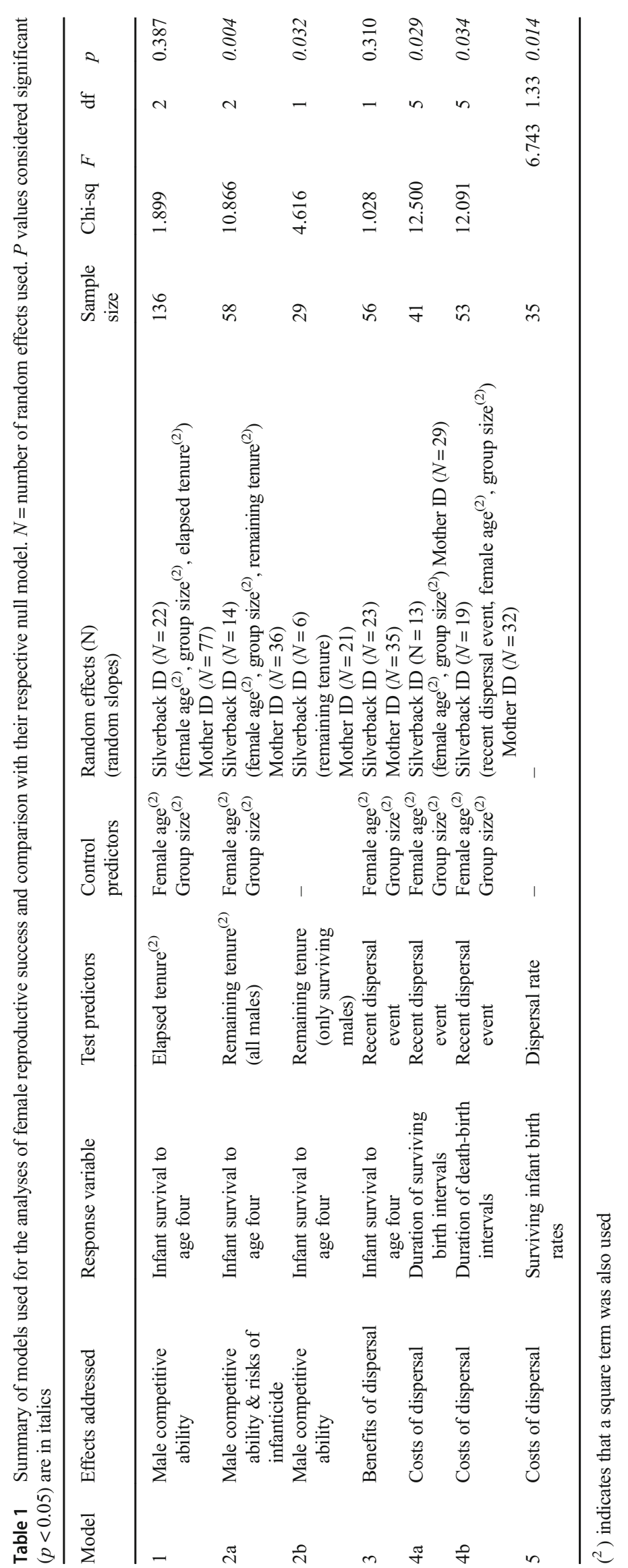


In all linear mixed models of surviving interbirth intervals, we included random effects for the identity of the mother and the identity of the group the infant was born into as well as all associated random slopes (Table 1). We z-transformed (to a mean of 0 and a standard deviation of 1) all quantitative predictor variables (female age and group size) and fitted the model by using the "Imer" function of the "Ime4" package (Bates et al. 2015) in $\mathrm{R}$ ( $\mathrm{R}$ Core Team 2017). We checked whether the residuals were homogeneous and normally distributed by visualizing a qqplot and the residuals plotted against fitted value, both indicating no obvious deviations from the assumptions. We checked for model stability by excluding subjects one at a time from the data and compared the derived model estimates with those from the full dataset, no influential subjects were found. Variance inflation factors (VIF) were derived from the function "vif" of the R-package "car" (Field 2005; Fox and Weisberg 2011) applied to a standard linear model excluding random effects and indicated no collinearity.

\section{Analyses of surviving birth rates}

To examine the combined impacts of female fertility and offspring survival, we fitted a linear model with Gaussian error structure testing how dispersal events affected the rate of giving birth to surviving offspring (surviving birth rate; SBR) of 35 females who were observed for at least 10 years of adulthood (model 5). The model included one data point for each female. Surviving birth rates were calculated as the number of surviving offspring, divided by the number of years a female was observed as an adult. The predictor variable was the number of transfers for each female. To reduce the potential effects of demographic stochasticity, each data point was weighted according to the duration of the observation per female (Robbins et al. 2006). We fitted the model using the function "lm" of the statistics package R (R Core Team 2017). A Gaussian was preferred over a Poisson error structure due to heavy underdispersion of the Poisson model. Checks of normality, homogeneity, and model stability were similar as for the IBI models.

\section{Results}

\section{Infant mortality}

Of the 229 infants that were born during the study period, $40 \%$ $(n=91)$ died before reaching age four, $40 \%(n=92)$ survived to the age of four, and $20 \%(n=46)$ were below age of four years at the end of the study. A survival analysis using all infants revealed an overall survival probability of $55 \%$ to age four. Infant mortality tended to be higher in early years of life (Pearson correlation: $r=0.943, n=4, p=0.057$, Fig. S1).
Infant mortality was not significantly correlated with the male elapsed tenure duration (model 1; Table 1). However, infant mortality was negatively correlated with the remaining male tenure duration, even when we excluded the infants born in groups in which the males had died (Model 2a, b in Tables 1 and 2; Fig. 3), suggesting that infants had a higher risk of mortality towards the end of a male tenure due to a potential decrease in male competitive ability as well as due to the risk of infanticide if the silverback dies. Infant mortality was as high as $78 \%$ for infants that were born during the last 5 years of a male's tenure compared with $39 \%$ before that time period (Fig. 3a). When we only used the remaining tenures of silverbacks whose tenures did not end because they died, the mortality was as high as $67 \%$ for infants that were born during the last 5 years of a male's tenure compared with $30 \%$ before (Fig. 3b). Mortality of infants born before and after a transfer event of females did not differ significantly (model 3 in Table 1) suggesting that transferring to another group does not provide a direct benefit of improved survival of her next offspring.

\section{Interbirth intervals}

The average duration of the surviving interbirth intervals was $67.0(\mathrm{SD}=11.0)$ months $(n=42$, range $=51.4-90.8)$. The length of the interbirth interval was dependent on whether a female transferred or not. Females who transferred after their offspring survived to age 4 years had an average SIBI of 69.6 \pm 12.0 months, which is significantly longer than an average SIBI of $64.8 \pm 10.8$ months for females who did not transfer (model 4a in Tables 1 and 3; Fig. 4a), representing a delay of $4.81(\mathrm{SD}=1.26)$ months. When females transferred after the death of an infant, they gave birth on average $8.7(\mathrm{SD}=8.0)$ months later than females who did not transfer. These females had an average DBI of 21.2 \pm 11.9 months, which is significantly longer than $12.6 \pm 3.9$ months for females who did not transfer (model 4b in Tables1 and 3; Fig. 4b).

\section{Surviving birth rates}

The dispersal costs were further tested using the surviving birth rates (SBR). Among the 35 females who were monitored for at least 10 years, we observed 100 births in 473 femaleyears (sum of number of years each female was an adult), which represents an overall birth rate of 0.21 offspring per female per year. Of those 100 offspring, 52 survived to age four, which represents a birth rate of 0.11 surviving offspring per female per year. The surviving birth rate per female was significantly negatively correlated with the number of transfers made by each female (Model 4a in Tables 1 and 3; Fig. 5). Specifically, the model shows that females have a birth rate of 0.14 surviving offspring per year if they never transferred compared with 0.06 surviving offspring per year if they transferred four times (Fig. 5). 
Table 2 Statistical details of Cox models testing the effects of male competitive ability and risk of infanticide (models 1 and 2 ) as well as benefits of dispersal (model 3 ) on infant survival probability. $P$ values considered significant $(p<0.05)$ are in italics

\begin{tabular}{|c|c|c|c|c|c|c|}
\hline Model & Fixed effect & Coefficient & $\operatorname{Exp}(\mathrm{coef})$ & $\mathrm{Se}(\mathrm{coef})$ & $z$ & $p$ \\
\hline \multirow[t]{6}{*}{1} & Elapsed tenure & -0.280 & 0.756 & 0.303 & -0.92 & 0.360 \\
\hline & Elapsed tenure squared & -0.008 & 0.992 & 0.200 & -0.04 & 0.970 \\
\hline & Group size & 0.009 & 1.001 & 0.224 & 0.04 & 0.970 \\
\hline & Group size $^{2}$ & 0.037 & 1.037 & 0.187 & 0.20 & 0.840 \\
\hline & Female age & 0.274 & 1.316 & 0.202 & 1.36 & 0.180 \\
\hline & Female age $^{2}$ & 0.212 & 1.236 & 0.175 & 1.21 & 0.230 \\
\hline \multirow[t]{6}{*}{$2 \mathrm{a}$} & Remaining tenure (all males) & -1.231 & 0.292 & 0.343 & -3.59 & $<0.001$ \\
\hline & Remaining tenure squared & 0.390 & 1.477 & 0.224 & 1.74 & 0.081 \\
\hline & Group size & -0.088 & 0.916 & 0.312 & -0.28 & 0.780 \\
\hline & Group size ${ }^{2}$ & -0.014 & 0.986 & 0.246 & -0.06 & 0.950 \\
\hline & Female age & -0.302 & 0.740 & 0.243 & -1.24 & 0.210 \\
\hline & Female age $^{2}$ & -0.158 & 0.854 & 0.154 & -1.03 & 0.300 \\
\hline $2 b$ & Remaining tenure (surviving males) & -0.997 & 0.369 & 0.463 & -2.16 & 0.031 \\
\hline \multirow[t]{5}{*}{3} & Dispersal event & 0.436 & 1.547 & 0.429 & 1.02 & 0.310 \\
\hline & Group size & 0.005 & 1.005 & 0.194 & 0.03 & 0.980 \\
\hline & Group size $^{2}$ & 0.191 & 1.210 & 0.193 & 0.99 & 0.320 \\
\hline & Female age & 0.581 & 1.788 & 0.239 & 2.43 & $0.015^{a}$ \\
\hline & Female age $^{2}$ & 0.095 & 1.099 & 0.211 & 0.45 & 0.660 \\
\hline
\end{tabular}

${ }^{\text {a }}$ Full-null model comparison (Table 1) is not significant

\section{Reproductive costs}

We ran post hoc calculations to assess whether the reproductive costs of longer interbirth intervals would outweigh the potential benefits of lower offspring mortality when females

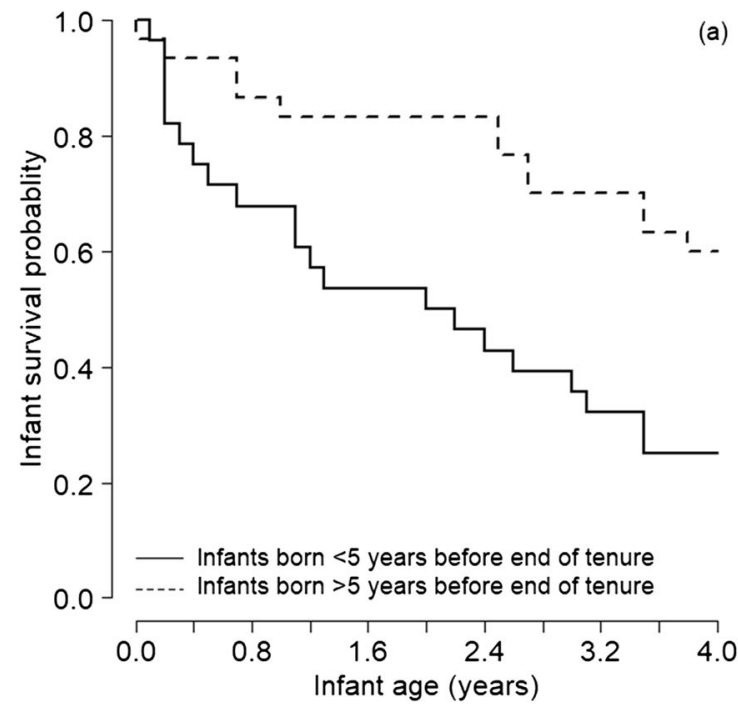

Fig. 3 Effect of remaining tenure duration on infant survival to age four for (a) infants born in groups where the tenure ended both with the death of the silverback and after the last female transferred out of the group and (b) for infants that were born into a group that ended with the transfer of transfer away from a silverback near the end of his tenure. The calculations used an equation from Robbins et al. (2009):

$\mathrm{rd}=\mathrm{DBI} \times\left(\left(\mathrm{M}_{\mathrm{c}}-\mathrm{M}_{\mathrm{a}}\right) /\left(1-\mathrm{M}_{\mathrm{c}}\right)\right)$

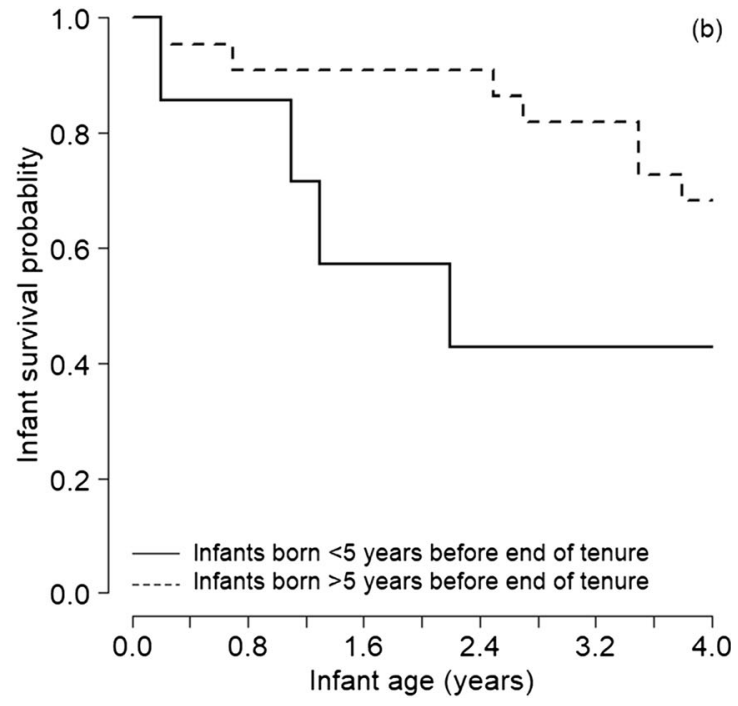

the last female. In both plots, the solid line is the survival probability of offsprings born $\leq 5$ years before the end of the tenure and the dotted line is the survival probability of offsprings born $>5$ years before the end of the tenure 
Table 3 Statistical details of linear and linear mixed models testing the effects of a dispersal event on two measures of female reproductive success: the duration of interbirth intervals (SIBI: model4a, DBI: model4b) and surviving infant birth rates. $P$ values considered significant $(p<0.05)$ are in italics

\begin{tabular}{llllll}
\hline Model & Fixed effect & Estimate & Standard error $t$ & $p$ \\
\hline $4 \mathrm{a}$ & (Intercept) & 5.183 & 0.241 & - & - \\
& Dispersal event & 0.627 & 0.255 & 2.459 & 0.019 \\
& Group size & -0.103 & 0.114 & -0.907 & 0.372 \\
& Group size squared & 0.078 & 0.136 & 0.577 & 0.513 \\
& Female age & -0.411 & 0.128 & -3.202 & $0.022^{a}$ \\
& Female age squared & 0.063 & 0.188 & 0.334 & 0.747 \\
$4 \mathrm{~b}$ & (Intercept) & 1.110 & 0.096 & - & - \\
& Dispersal event & 0.918 & 0.264 & 3.472 & 0.002 \\
& Group size & -0.008 & 0.067 & -0.120 & 0.886 \\
& Group size squared & -0.063 & 0.061 & -1.030 & 0.287 \\
& Female age & 0.085 & 0.065 & 1.315 & 0.170 \\
& Female age squared & 0.001 & 0.052 & 0.017 & 0.993 \\
5 & (Intercept) & 0.142 & 0.016 & - & - \\
& Dispersal event & -0.020 & 0.008 & 2.597 & 0.011 \\
\hline
\end{tabular}

${ }^{a}$ Female age was not significant in a reduced model without the squared terms

in which $M_{\mathrm{c}}$ is the infant mortality rate in their current group ( $78 \%$ with a silverback $<5$ years away from the end of his tenure), $M_{\mathrm{a}}$ is the expected mortality rate in the dispersal destination $(39 \%$ with a silverback $>5$ years away from the end of his tenure), and DBI is the average length of interbirth intervals when an infant dies (21.2 months). The equation indicates that a female could tolerate a reproductive delay (rd) of up to 37.6 months, while still increasing their expected reproductive success through the dispersal. Thus, the equation suggests that the observed reproductive delays (4.81 months for SIBI) should not prevent females from increasing their reproductive success by dispersing to avoid high infant mortality at the end of a male tenure.

\section{Discussion}

In western lowland gorillas, females experience sexual coercion by males (Robbins et al. 2013; Breuer et al. 2016) and respond by seeking the protection of powerful males. Despite the limitation of the data, our results show that offspring mortality increases towards the end of the male's tenure, (presumably due to declining strength of the silverback), such that females are faced with the trade-off between staying and risking higher infant mortality (because the silverback loses competitive ability and eventually dies) versus transferring and suffering the costs of longer interbirth intervals and lower birth rates. If females transfer to counter the effects of malemale competition and sexual coercion, then, our study demonstrates that female reproductive strategies were not sufficient to overcome the adverse consequences of male behavior.

\section{Reproductive costs of male tenure duration}

When considering all tenures that ended, infant mortality was higher for infants born towards the end of the tenure (78\% infant mortality within the last 5 years to end of tenure). This high mortality is most likely due to infanticide when the female transfers to a new male after the death of the current silverback (Stokes et al. 2003; Breuer et al. 2010). This result supports the argument and findings in many other species that killing an unweaned offspring will accelerate the return of the
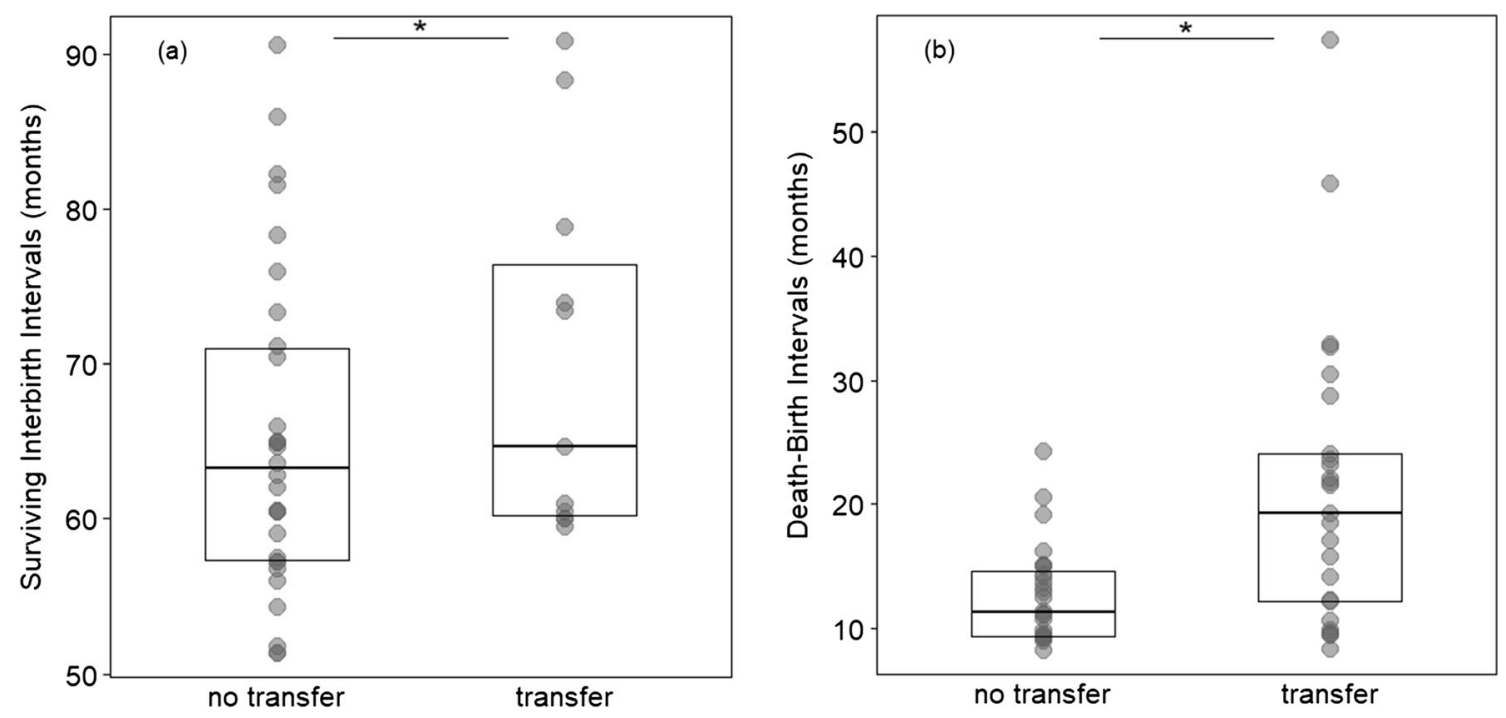

Fig. 4 Interbirth intervals and transfer event. Interbirth intervals after a surviving offspring (a) and after the death of the last offspring (b). Boxes represent medians and upper and lower quartiles. Dotted lines link interbirth intervals of the same females. The one asterisk above each plot represents a $P<0.05$ 


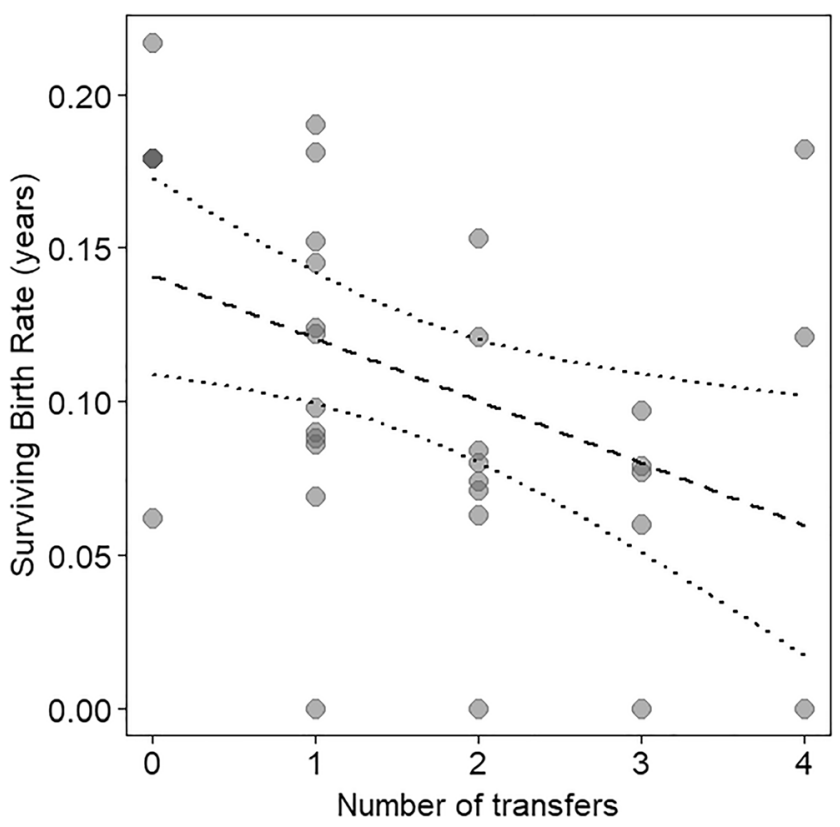

Fig. 5 Surviving birth rates as a function of the number of voluntary female transfers. Each point represents one female that was observed for longer than 10 years. The dashed lines represent the fitted model and its $95 \%$ confidence limits

female to a breeding state and allow the new silverback to raise his own offspring (van Schaik and Janson 2000; Cheney et al. 2004; Lukas and Huchard 2014).

However, our results also show that infant mortality was still higher at the end of the tenure, even if the silverback did not die (67\% within the last 5 years to the end of the tenure), suggesting that silverbacks may be less capable of protecting their offspring as they reached the end of their tenure; in many case, they are old and presumably declining in strength. Western lowland gorilla silverbacks near the end of their tenure may have difficulties in keeping other males away from females during aggressive group encounters similar to observation in Thomas langur males (Steenbeek 2000). Extra-group male Thomas langurs have been observed to perform both infanticide and aggression towards females during these encounters (Steenbeek 1999), potentially explaining why males near the end of their tenure may avoid other groups or interact with them less frequently (Steenbeek 2000). Western lowland gorilla males near the end of their tenure have also been observed avoiding other groups in the clearing of Mbeli Bai (Mbeli Bai Study, MM pers. obs.) although this has not been statistically tested yet. If silverbacks near the end of their tenure avoid other groups, it is possible that they lose access to high-quality habitat. Infant mortality may therefore not only be due to infanticide or aggression during intergroup encounters but also suffer reduced access to high-quality food, but this idea remains to be tested. Females may therefore avoid the costs of higher infant mortality when with a silverback near the end of his tenure, (who may exhibit signs of senescence or declining strength), by transferring to another silverback (van
Schaik 1996; Sterck et al. 1997; Sicotte 2001). In gorillas, this is also supported by the tendency for females to emigrate following the death of an infant (Watts 1989; Stokes et al. 2003). Although larger silverbacks have been found to have more females in their group and higher offspring survival (Breuer et al. 2012), their strength is likely to vary over time. Female gorillas could assess the current strength, fighting ability, and health of their silverbacks by the intensity or duration of their threat displays occurring during intergroup encounters (Sicotte 2001; Breuer et al. 2012). Nonetheless, the ability of female gorillas to avoid infanticide may still be limited by the difficulties of predicting how the strength of their silverback will change throughout infancy of their next offspring.

Against our expectations, we found no evidence that infant mortality was higher in the beginning of a male's tenure and decreased with time. In fact, we found that infant mortality increased as a silverback was further along in his tenure, although this pattern was not statistically significant, suggesting that some elapsed tenures may be almost complete tenures and already show the pattern found at the end of a male's tenure. Male competitive ability often peaks during early adulthood in species in which males acquire females by forming a group (Dunbar 2013), and our results suggest that silverbacks may only be successful in starting a group when they are physically strong enough to fight off predators or other males. Solitary males will typically have adequate strength to defend groups when females join them. Young silverbacks may also have fewer females, which in turn may make it easier to protect them or females could choose males in their prime or emigrate away from young, inexperienced males as in lions (Pusey and Packer 1994). A detailed study of female dispersal patterns, including whether females preferentially disperse to younger or older silverbacks, is ongoing (MLM et al., unpubl. data).

\section{Reproductive delays with dispersal}

Dispersal costs have been found in several species of birds and mammals (Bonte et al. 2012; Debeffe et al. 2015). Our results show that dispersal has costs on subsequent reproductive attempts for adult female lowland gorillas because the duration of the surviving interbirth interval was on average 5 months longer when it included a transfer event, which is similar to the delay observed in mountain gorillas (Robbins et al. 2009). Besides the reproductive delay, female lowland gorillas who transferred multiple times in their lives had reduced surviving birth rates, suggesting that dispersal may also have long-term consequences on female reproductive success. However, we cannot exclude that females experiencing higher infant mortality were also more likely to transfer (Shafer et al. 2011; Gueijman et al. 2013). Nevertheless, these reproductive delays 
are substantial because they can as much as half the number of surviving offspring born to a female over her lifetime. Our analysis suggests that females that transfer four times over their reproductive lifespan would need approximately 17 years to produce a surviving offspring (surviving birth rate of 0.06/ year) compared with 7 years for females that never transfer (surviving birth rate of 0.14 /year). With such a high cost, females should avoid transferring unless it represents a substantial benefit for future reproduction.

\section{Trade-off between staying versus transferring}

Our calculations suggest that the observed reproductive costs of longer interbirth intervals do not outweigh the potential benefits of lower offspring mortality when females transfer away from a silverback near the end of his tenure. Several additional factors could also come into play when female gorillas face the trade-off between staying in their current group and risk the cost of infant mortality versus dispersing and facing a reproductive delay. They have a limited time window in which to disperse between when their current infant is weaned and before conceiving again because it is unlikely that they will transfer when they are pregnant or lactating due to the risk of infanticide (Sterck et al. 2005; Robbins et al. 2009). This time window is approximately 4 months (as calculated with the 12.5 months DBI minus 8.5 months gestation period). The observed DBI suggest that females barely need a recovery period for themselves between end of lactation and next conception (similar to orangutans, van Noordwijk et al. 2018), yet female gorillas could use this 4 months period to weigh their options of staying versus leaving. Females may try to delay reproduction until they can transfer to a more suitable partner, as found for Thomas's langurs (Steenbeek 2000), but if such a mate is not found during this limited time window or if the current silverback actively prevents them from transferring, females may stay and conceive again with a weak silverback and thus suffer a high infanticide risk if their current silverback dies.

The risk of injury from male coercion during intergroup encounters can represent a cost of attempting dispersal for female gorillas and may prevent them from transferring (Watts 1991; Robbins 2009; Breuer et al. 2016). Potential migrant females (females without weaned offspring and not pregnant) at Mbeli received significantly more aggression when the group encountered a silverback, which supports this assumption. Furthermore, females in larger groups received less aggression, suggesting that it may be easier to transfer away from a group with more females (Breuer et al. 2016). After a successful transfer, females may still need several months to conceive after joining a new group due to aggression by resident females (Watts 1992; Harcourt and Stewart 2007), resident females actively preventing newly transferred females from mating leading to delayed conception (Doran-Sheehy et al. 2009), unfamiliarity with the new habitat
(Isbell and Van Vuren 1996), or uncertainty about the protective abilities of the new male as in lions (Pusey and Packer 1994).

Despite these potential costs suffered by dispersing females, female secondary dispersal is common in lowland gorillas (Stokes et al. 2003) suggesting that the benefits of transfer can overall outweigh the costs of staying in the current group (Clutton-Brock and Lukas 2012). If females can leave a male near the end of his tenure before conceiving again and transfer to a younger male at the beginning of his tenure, these dispersal benefits may far outweigh the costs of staying with a male reaching the end of his tenure. On the other hand, if silverbacks at the beginning of their tenure attract more females, higher mating competition among females may be expected (DoranSheehy et al. 2009) or higher within-group feeding competition, although our results did not show that female reproductive success was influenced by the size of the group. If females transfer to a more competitive male, infant mortality is expected to be lower after a transfer event; however, we did not find evidence of female transfer affecting infant survival, similar to observations of Thomas langurs (Sterck et al. 1997). In conclusion, transfer decisions are likely made based on the sum of many factors, with the ultimate aim of maximizing female reproductive success via shorter interbirth intervals and lower infant mortality that result in higher surviving birth rates. Because females suffer the highest costs when with a male reaching the end of his tenure, the timing of dispersal may be a key to improve reproductive success.

\section{Implications for evolution of social systems}

The social organization of primates is believed to be influenced by feeding competition, predator avoidance, and reproductive strategies (Schülke and Ostner 2012). Our results suggest that male strategies can impose substantial costs on females, despite female counterstrategies of secondary dispersal (Harcourt and Stewart 2007; Pradhan and van Schaik 2008), and may explain why female secondary dispersal is so rare among mammals (Dobson 2013) and occurs primarily in species with strong male-male competition, which results in ephemeral one-male groups that last only for the duration of male tenures (Steenbeek 1999). This is in contrast to many primate species living in multimale-multifemale social groups that exist for many generations, primarily with female philopatry. Thus, the influence of sexual conflict on social systems may be just as important as ecological factors in some species (Sterck et al. 1997; van Schaik and Kappeler 1997). Additional long-term data on behavioral strategies and reproductive success should help to further disentangle the impacts of these factors on the evolution of different social systems found in primates (Clutton-Brock and Janson 2012).

Acknowledgments We thank the Ministry of Sustainable Development, Forest Economy and Environment and the Ministry of Scientific 
Research of the republic of Congo for permission to conduct field work in the Nouabalé Ndoki National Park. We also thank the Wildlife Conservation Society - Congo Program and the Nouabalé Ndoki Foundation for logistical and administrative support. We are grateful to Claudia Olejniczak, Kelly Greenway, Jana Robeyst, Vidrige Kandza, Frank Mavinga, Mireille Breuer-Ndoundou Hockemba, and numerous research assistants for their help monitoring Mbeli Bai over the years. Many thanks to Roger Mundry and Colleen Stephens for their valuable advice in conducting the data analysis. For their advice and revisions of previous versions of this manuscript, we thank Christophe Boesch, Edward Wright, Laura Hagemann, Julia Metsio Sienne, Maria van Noordwijk, and two anonymous reviewers. We are also grateful to the numerous donors who supported the Mbeli Bai Study over the last two decades, notably: The Columbus Zoo and Aquarium, Cincinnati Zoo and Botanical Garden, Cologne Zoo, Disney Worldwide Conservation Fund, Dublin Zoo, Sea World and Bush Gardens Conservation Fund, Toronto Zoo, Wildlife Conservation Society, and Woodland Park Zoo.

Funding Information Open access funding provided by Max Planck Society. MLM received a research grant from the German Academic Exchange Program (DAAD) and a stipend from the Max Planck Institute for evolutionary Anthropology.

Data availability The data used for this study are available from the corresponding author on request.

\section{Compliance with ethical standards}

Conflict of interest The authors declare that they have no conflicts of interest.

Ethical approval This study involved observation of animals in their natural habitat and was not disruptive to the subjects and the ecosystem. All observations were made from a $9 \mathrm{~m}$ high platform and animals were mostly unaware of the presence of the researchers. All study procedures complied with the national laws and regulations of the respective country, as well as the ethical standards of the Max Planck Institute for Evolutionary Anthropology and the Primatology department's ethical guidelines for non-invasive research, and the Comité d'Ethique de la Recherche en Sciences de la Santé in Brazzaville, Republic of Congo.

Open Access This article is distributed under the terms of the Creative Commons Attribution 4.0 International License (http:// creativecommons.org/licenses/by/4.0/), which permits unrestricted use, distribution, and reproduction in any medium, provided you give appropriate credit to the original author(s) and the source, provide a link to the Creative Commons license, and indicate if changes were made.

\section{References}

Alberts SC (2012) Magnitude and sources of variation in male reproductive performance. In: Mitani JC, Call J, Kappeler PM, Palombit RA, Silk JB (eds) The evolution of primate societies. University of Chicago Press, Chicago, pp 412-431

Arnott G, Elwood RW (2009) Assessment of fighting ability in animal contests. Anim Behav 77:991-1004

Arnqvist G, Rowe L (2013) Sexual conflict. Princeton University Press, Princeton

Bates D, Maechler M, Bolker B, Walker S (2015) Fitting linear mixedeffects models using lme4. J Stat Softw 67:1-48
Bonte D, Van Dyck H, Bullock JM, Coulon A, Delgado M, Gibbs M, Lehouck V, Matthysen E, Mustin K, Saastamoinen M (2012) Costs of dispersal. Biol Rev 87:290-312

Breuer T, Hockemba MB-N, Olejniczak C, Parnell RJ, Stokes EJ (2009) Physical maturation, life-history classes and age estimates of freeranging western gorillas - insights from Mbeli Bai, Republic of Congo. Am J Primatol 71:106-119. https://doi.org/10.1002/ajp. 20628

Breuer T, Robbins AM, Olejniczak C, Parnell RJ, Stokes EJ, Robbins MM (2010) Variance in the male reproductive success of western gorillas: acquiring females is just the beginning. Behav Ecol Sociobiol 64:515-528. https://doi.org/10.1007/s00265-009-0867-6

Breuer T, Robbins AM, Boesch C, Robbins MM (2012) Phenotypic correlates of male reproductive success in western gorillas. J Hum Evol 62:466-472. https://doi.org/10.1016/j.jhevol.2012.01.006

Breuer T, Robbins AM, Robbins MM (2016) Sexual coercion and courtship by male western gorillas. Primates 57:29-38

Caillaud D, Levréro F, Gatti S, Menard N, Raymond M (2008) Influence of male morphology on male mating status and behavior during interunit encounters in western lowland gorillas. Am J Phys Anthropol 135:379-388. https://doi.org/10.1002/ajpa.20754

Cheney DL, Seyfarth RM, Fischer J, Beehner J, Bergman T, Johnson SE, Kitchen DM, Palombit RA, Rendall D, Silk JB (2004) Factors affecting reproduction and mortality among baboons in the Okavango Delta, Botswana. Int J Primatol 25:401-428

Clobert J, Baguette M, Benton TG, Bullock JM, Ducatez S (2012) Dispersal ecology and evolution. Oxford University Press, Oxford

Clutton-Brock T (2007) Sexual selection in males and females. Science 318:1882-1885

Clutton-Brock TH, Huchard E (2013) Social competition and selection in males and females. Philos Trans R Soc B 368:20130074

Clutton-Brock T, Janson C (2012) Primate socioecology at the crossroads: past, present, and future. Evol Anthropol 21:136-150. https://doi.org/10.1002/evan.21316

Clutton-Brock TH, Lukas D (2012) The evolution of social philopatry and dispersal in female mammals. Mol Ecol 21:472-492

Debeffe L, Richard E, Medill SA, Weisberger JN, McLoughlin PD (2015) Costs of social dispersal in a polygynous mammal. Behav Ecol 26: 1476-1485

Di Fiore A, Link A, Schmitt CA, Spehar SN (2009) Dispersal patterns in sympatric woolly and spider monkeys: integrating molecular and observational data. Behaviour 146:437-470

Dobson FS (2013) The enduring question of sex-biased dispersal: Paul J. Greenwood's (1980) seminal contribution. Anim Behav 85:299304

Dobson AJ, Barnett A (2008) An introduction to generalized linear models. CRC press, Boca Raton

Doran-Sheehy DM, Fernández D, Borries C (2009) The strategic use of sex in wild female western gorillas. Am J Primatol 71:1011-1020

Dunbar RIM (2013) Primate social systems. Springer Science and Business Media, Berlin

Field A (2005) Regression. Discovering statistics using SPSS. Sage Publications, London

Forstmeier W, Schielzeth H (2011) Cryptic multiple hypotheses testing in linear models: overestimated effect sizes and the winner's curse. Behav Ecol Sociobiol 65:47-55

Fox J, Weisberg S (2011) An R companion to applied regression. Thousand Oaks, Los Angeles

Furuichi T, Yamagiwa J, Aureli F (2015) Dispersing primate females: life history and social strategies in male-philopatric species. Springer, Berlin

Gatti S, Levréro F, Ménard N, Gautier-Hion A (2004) Population and group structure of western lowland gorillas (Gorilla gorilla gorilla) at Lokoue, republic of Congo. Am J Primatol 63:111-123 
Gueijman A, Ayali A, Ram Y, Hadany L (2013) Dispersing away from bad genotypes: the evolution of fitness-associated dispersal (FAD) in homogeneous environments. BMC Evol Biol 13:125

Hagemann L, Boesch C, Robbins MM, Arandjelovic M, Deschner T, Lewis M, Froese G, Vigilant L (2018) Long-term group membership and dynamics in a wild western lowland gorilla population (Gorilla gorilla gorilla) inferred using non-invasive genetics. Am J Primatol 80:1-12

Harcourt AH, Stewart KJ (2007) Gorilla society: conflict, compromise, and cooperation between the sexes. Chicago University Press, Chicago

Harcourt AH, Stewart K, Fossey D (1976) Male emigration and female transfer in wild mountain gorilla. Nature 263:226-227

Hrdy SB (1977) Infanticide as a primate reproductive strategy. Am Sci 65:40-49

Isbell LA, Van Vuren D (1996) Differential costs of locational and social dispersal and their consequences for female group-living primates. Behaviour 133:1-36

Janson C, Baldovino MC, Di Bitetti M (2012) The group life cycle and demography of brown capuchin monkeys (Cebus [apella] nigritus) in Iguazú National Park, Argentina. In: Kappeler PM, Watts DP (eds) Long-term field studies of primates. Springer, Berlin, pp $185-212$

Kalbitzer U, Bergstrom ML, Carnegie SD, Wikberg EC, Kawamura S, Campos FA, Jack KM, Fedigan LM (2017) Female sociality and sexual conflict shape offspring survival in a Neotropical primate. Proc Natl Acad Sci U S A 114:1892-1897

Kappeler PM, van Schaik CP (2002) Evolution of primate social systems. Int J Primatol 23:707-740

Lewis RJ (2018) Female power in primates and the phenomenon of female dominance. Annu Rev Anthropol 47:533-551

Lukas D, Huchard E (2014) The evolution of infanticide by males in mammalian societies. Science 346:841-844

Markham AC, Gesquiere LR, Alberts SC, Altmann J (2015) Optimal group size in a highly social mammal. Proc Natl Acad Sci U S A 112:14882-14887

Nagy M, Heckel G, Voigt CC, Mayer F (2007) Female-biased dispersal and patrilocal kin groups in a mammal with resource-defence polygyny. Proc R Soc Lond B 274:3019-3025

Nowell AA, Fletcher AW (2007) Development of independence from the mother in Gorilla gorilla gorilla. Int J Primatol 28:441-455

Packer C, Pusey AE (1983) Male takeovers and female reproductive parameters: a simulation of oestrous synchrony in lions (Panthera leo). Anim Behav 31:334-340. https://doi.org/10.1016/S00033472(83)80051-7

Palombit RA (2015) Infanticide as sexual conflict: coevolution of male strategies and female counterstrategies. CSH Perspect Biol 7:1-29

Parnell RJ (2002) Group size and structure in western lowland gorillas (Gorilla gorilla gorilla) at Mbeli Bai, Republic of Congo. Am J Primatol 56:193-206

Plavcan JM, van Schaik CP (1997) Intrasexual competition and body weight dimorphism in anthropoid primates. Am J Phys Anthropol 103:37-68

Pradhan GR, van Schaik C (2008) Infanticide-driven intersexual conflict over matings in primates and its effects on social organization. Behaviour 145:251-275

Pusey A (2012) Magnitude and sources of variation in female reproductive performance. In: Mitani JC, Call J, Kappeler PM, Palombit RA, Silk JB (eds) The evolution of primate societies. University of Chicago Press, Chicago, pp 343-366

Pusey AE, Packer C (1994) Infanticide in lions: consequences and counterstrategies. In: Parmigiani S, vom Saal F (eds) Infanticide and parental care. Harwood Academic Publ, London, pp 277-299

R Core Team (2017) R: a language and environment for statistical computing. R Foundation for Statistical Computing, Vienna, Austria. http://www.R-project.org. Accessed 16 Apr 2018
Robbins MM (2009) Male aggression against females in mountain gorillas: courtship or coercion. In: Muller MN, Wrangham RW (eds) Sexual coercion in primates: an evolutionary perspective on male aggression against females. Harvard University Press, Cambridge, pp $112-127$

Robbins MM, Robbins AM (2018) Variation in the social organization of gorillas: life history and socioecological perspectives. Evol Anthropol 27:218-233

Robbins AM, Robbins MM, Gerald-Steklis N, Steklis HD (2006) Agerelated patterns of reproductive success among female mountain gorillas. Am J Phys Anthropol 131:511-521

Robbins MM, Robbins AM, Gerald-Steklis N, Steklis HD (2007) Socioecological influences on the reproductive success of female mountain gorillas (Gorilla beringei beringei). Behav Ecol Sociobiol 61:919-931

Robbins AM, Stoinski TS, Fawcett KA, Robbins MM (2009) Does dispersal cause reproductive delays in female mountain gorillas? Behaviour 146:525-549

Robbins AM, Gray M, Basabose A, Uwingeli P, Mburanumwe MM (2013) Impact of male infanticide on the social structure of mountain gorillas. PLoS One 8:e78256

Rudran R (1973) Adult male replacement in one-male troops of purplefaced langurs (Presbytis senex senex) and its effect on population structure. Folia Primatol 19:166-192

Schielzeth H (2010) Simple means to improve the interpretability of regression coefficients. Methods Ecol Evol 1:103-113

Schülke O, Ostner J (2012) Ecological and social influences on sociality. In: Mitani JC, Call J, Kappeler PM, Palombit RA, Silk JB (eds) The evolution of primate societies. University of Chicago Press, Chicago, pp 195-219

Shafer AB, Poissant J, Côté SD, Coltman DW (2011) Does reduced heterozygosity influence dispersal? A test using spatially structured populations in an alpine ungulate. Biol Lett 7:433-435

Sicotte P (2001) Female mate choice in mountain gorillas. In: Robins MM, Sicotte P, Stewart KJ (eds) Mountain gorillas: three decades of research at Karisoke. Cambridge University Press, Cambridge, pp 59-87

Smuts BB, Smuts RW (1993) Male aggression and sexual coercion of females in nonhuman primates and other mammals: evidence and theoretical implications. Adv Study Behav 22:1-63

Steenbeek R (1999) Tenure related changes in wild Thomas's langurs I: between-group interactions. Behaviour 136:595-625

Steenbeek R (2000) Infanticide by males and female choice in wild Thomas's langurs. In: Infanticide by Males and its Implications. Cambridge University Press, pp 153-177

Sterck EHM, Korstjens AH (2000) Female dispersal and infanticide avoidance in primates. In: van Schaik CP, Janson $\mathrm{CH}$ (eds) Infanticide by males and its implications. Cambridge University Press, Cambridge, pp 293-321

Sterck EHM, Watts DP, van Schaik CP (1997) The evolution of female social relationships in nonhuman primates. Behav Ecol Sociobiol 41:291-309

Sterck EHM, Willems EP, van Hooff JARAM, Wich SA (2005) Female dispersal, inbreeding avoidance and mate choice in Thomas langurs (Presbytis thomasi). Behaviour 142:845-868

Stevenson PR, Zárate DA, Ramírez MA, Henao-Díaz F (2015) Social interactions and proximal spacing in woolly monkeys: lonely females looking for male friends. In: Furuichi T, Yamagiwa J, Aureli F (eds) Dispersing primate females. Springer, Tokyo, pp 45-71

Stokes EJ, Parnell RJ, Olejniczak C (2003) Female dispersal and reproductive success in wild western lowland gorillas (Gorilla gorilla gorilla). Behav Ecol Sociobiol 54:329-339

Strier KB (1994) Myth of the typical primate. Am J Phys Anthropol 37: 233-271 
Swedell L, Saunders J, Schreier A, Davis B, Tesfaye T, Pines M (2011) Female "dispersal" in hamadryas baboons: transfer among social units in a multilevel society. Am J Phys Anthropol 145:360-370

Therneau TM (2018) Coxme: mixed effects cox models. CRAN repository. http://cran.r-project.org/package=coxme. Accessed 23 Aout 2018

Trivers R (1972) Parental investment and sexual selection. In: Campbell B (ed) Sexual selection and the descent of man. Aldine Publishing, Chicago, pp 136-179

van Noordwijk MA, Atmoko SSU, Knott CD, Kuze N, Morrogh-Bernard HC, Oram F, Schuppli C, van Schaik CP, Willems EP (2018) The slow ape: high infant survival and long interbirth intervals in wild orangutans. J Hum Evol 125:38-49

van Schaik CP (1996) Social evolution in primates: the role of ecological factors and male behaviour. Proc Brit Acad 88:9-32

van Schaik CP, Janson CH (eds) (2000) Infanticide by males and its implications. Cambridge University Press, Cambridge van Schaik CP, Kappeler PM (1997) Infanticide risk and the evolution of male-female association in primates. Proc R Soc Lond B 264:16871694

Watts DP (1989) Infanticide in mountain gorillas: new cases and a reconsideration of the evidence. Ethology 81:1-18

Watts DP (1991) Mountain gorilla reproduction and sexual behavior. Am J Primatol 24:211-225

Watts DP (1992) Social relationships of immigrant and resident female mountain gorillas. I. Male-female relationships. Am J Primatol 28: $159-181$

Wright E, Galbany J, McFarlin SC, Ndayishimiye E, Stoinski TS, Robbins MM (2019) Male body size, dominance rank and strategic use of aggression in a group-living mammal. Anim Behav 151:87102

Publisher's note Springer Nature remains neutral with regard to jurisdictional claims in published maps and institutional affiliations. 